\title{
Prevalence of Dementia and Its Associated Factors in Cotonou Teaching Hospital, Benin
}

\author{
Dieu Donné Gnonlonfoun1*, Constant Adjien1, Paul Macaire Ossou-Nguiet², \\ Lansana Laho Diallo ${ }^{3}$, Octave Houannou${ }^{1}$, Jocelyn Acakpo ${ }^{4}$, Gérard Goudjinou${ }^{1}$, \\ Dismand Houinato' ${ }^{1}$, Dossou Gilbert Avode ${ }^{1}$ \\ ${ }^{1}$ Neurology Department, CNHU-HKM of Cotonou, Cotonou, Benin \\ ${ }^{2}$ Neurology Department, Brazzaville Teaching Hospital, Brazzaville, Congo \\ ${ }^{3}$ Neurology Department, Conakry Teaching Hospital, Conakry, Guinea \\ ${ }^{4}$ Epidemiology Institute, FSS/UAC, Cotonou, Benin \\ Email: * dignon2002@yahoo.fr
}

Received 18 February 2014; revised 21 March 2014; accepted 31 March 2014

Copyright (C) 2014 by authors and Scientific Research Publishing Inc.

This work is licensed under the Creative Commons Attribution International License (CC BY).

http://creativecommons.org/licenses/by/4.0/

(c) (i) Open Access

\section{Abstract}

Introduction: Dementia constitutes a public health hazard in developing countries. There is little data in the sub-Saharan region of African especially in Benin. Objective: Determining dementia hospitalization prevalence and identifying its associated factors in CNHU-HKM, Cotonou. Method: It was a cross-sectional, prospective, descriptive and analytical research conducted from October 2012 to July 2013 in the neurology department; it involved 251 patients aged 50 and above. Dementia screening was conducted using a modified and adapted Mini Mental Scale Examination (MMSE). Dementia clinical and etiological diagnoses were respectively conducted based on DMS-IV and HACHINSKI criteria. Results: Patients were averagely aged $60.9 \pm 8.1$. Sex ratio (Male/Female) was 1.07 . Dementia prevalence was $8.8 \%$. This rate increased proportionally with age, from $5.3 \%$ with patients aged below 60 to $12.7 \%$ with patients aged above 60 . Degenerative dementia was the most predominant type (50\%). Following multi-varied analysis, smoking (RC $=6.05$ [IC 95\% $=$ $1.26-29.38] \mathrm{p}=0.0001$ ) and stroke past records $(\mathrm{RC}=6.05[\mathrm{IC} 95 \%=1.26-29.38] \mathrm{p}=0.001$ ) revealed to be the factors associated with dementia. Conclusion: This research showed that dementia affects a significant part of the aging population in CNHU-HKM. It is imperative to combat its associated factors so as to defuse its prevalence.

\section{Keywords}

Prevalence, Dementia, Elders, MMSE, DSMIV, Cotonou, Benin

\footnotetext{
*Corresponding author.
}

How to cite this paper: Gnonlonfoun, D.D., Adjien, C., Ossou-Nguiet, P.M., Diallo, L.L., Houannou, O., Acakpo, J., Goudjinou, G., Houinato, D. and Avode, D.G. (2014) Prevalence of Dementia and Its Associated Factors in Cotonou Teaching Hospital, Benin. Advances in Alzheimer's Disease, 3, 94-106. http://dx.doi.org/10.4236/aad.2014.32010 


\section{Introduction}

In sub-Saharan Africa, the gradual improvement of living conditions is correlated with life span increase. The end result is the increasing emergence of certain pathologies associated with age, among others, dementia [1]. Dementia syndrome is defined as a global cognitive decline in a person with a normal state of consciousness. Its occurrence and development are progressive. The Pathophysiology is dependent on the cause. Dementia occurs through accelerating apoptosis. AD is the commonest among neurodegenerative dementias; it is predominantly cortical. There are two types of brain damage resulting in AD: senile plaques (amyloidogenesis) and neurofibrillary tangles. Preferentially, the lesions affect the limbic system. In parallel, during fibrillary degeneration, pathologic filaments comprised of TAU proteins build up around the cell bodies of neurons. Several factors such as ageing, environment and genetic interrelate then causing dementia [2]. Dementia diagnosis is referred to a progressive and acquired memory deterioration associated with a disorder of at least one of the other cognitive functions. It results in social and occupational impairment, as well as difficulties in carrying out daily activities, not forgetting loss of autonomy [3]. It has become a public health hazard. In 2005 the number of dementia patients was estimated at 24.3 million worldwide, and 4.6 million new cases recorded yearly. This figure will reach 81.1 million by 2040 [2]. Worldwide, dementia is one of the major causes of disability and dependency in elderly population. It has physical, psychological, social and economic consequences on care givers, families and society. There is hardly any epidemio-clinical data on dementia in Africa [3] [4] particularly in Benin [5] [6]. So, this research was initiated to determine dementia hospitalization prevalence and identify its associated factors.

\section{Method}

It consists in a cross-sectional, prospective, descriptive and analytical research conducted from October 1, 2012 to July 30, 2013 in Hubert Koutoukou Maga teaching hospital of Cotonou Benin. Benin is a French-speaking country located in West African (Figure 1), sharing border with Nigeria on the east. It boasts of 9 million inhabitants with an area of $112,622 \mathrm{~km}^{2}$. The population subjected to the research consisted of patients who went through consultation in the neurology department during research period. The sample size was calculated using Daniel Schwartz formulae $\mathrm{n}=\mathrm{Z} \alpha^{2} \mathrm{pq} / \mathrm{i}^{2}=182$ with $\mathrm{p}=13.79 \%$ (dementia prevalence in neurology department of CNHU-HKM in 1991 [5], $\alpha=5 \%$ and $\mathrm{I}=5 \%$. The total number of subjects enrolled in the research was 251. But during the study period, we performed a systematic enrollment of all patients who met the inclusion criteria and consented to participate in the research, up to the number expected.

Inclusion criteria

- $\quad$ Be aged 50 and above.

- Having been consulted in the neurology department during research period.

\section{Exclusion criteria}

- Having experienced language disorder.

- Having been diagnosed as experiencing continuous confusional episode, chronic psychosis and depressive syndrome.

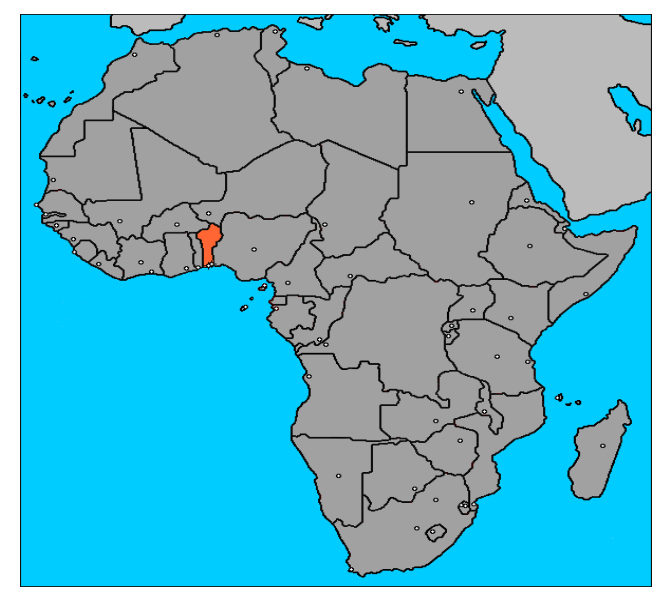

Figure 1. Position of Benin in Africa. 


\section{Diagnosis Criteria}

Patients were subjected to their cognitive functions evaluation through Mini Mental State Examination (MMSE) in its modified version which is adapted to the research cultural era. Patients who recorded MMSE $\leq 24 / 30$ are likely to have dementia and subjected to DSM IV criteria [7] for dementia diagnosis. Its severity is appreciated in conformity with MMSE score. In fact,

- a score 20/30 $\leq$ MMSE $\leq 24 / 30$ with a patient matching DMS IV criteria, is considered as "moderate dementia".

- a score MMSE $\leq$ à 19/30 with a patient matching DMS IV criteria, is considered as "severe dementia".

HACHINSKI score was used to determine the nature of the effect:

- >7: vascular dementia.

- Between 4 and 7: mixed dementia.

- $\quad<7$ degenerative dementia.

The Variables Studied Were

Dependent variable: dementia.

Independent variables: they were:

- Socio-demographic: age, gender, ethnicity, profession, residence, marital status, number of children, education level.

- Clinical: Hypertension, diabetes, obesity, stroke, cardiomyopathy, sinusitis, epilepsy hyperlipidemia.

- Types of dementia: curable dementia, vascular dementia, degenerative dementia, mixed dementia.

Data Processing and Analysis

Data processing was conducted through EPI-DATA. Data analysis was done using statistics software STATA/ IC 11.0. A descriptive analysis was completed with regard to the variables which were studied. So, for qualitative variables, frequencies and proportions were determined. Either chi 2 or FISHER test was used if only expected values are lower than 5 . For quantitative values, averages together with their typical gaps, medians, minima and maxima have all been described. STUDENT test was utilized for comparisons purpose. The study of associated factors was conducted using logistical regression model in unvaried and multi-varied analyses. The multi-varied analysis was conducted by inserting into the model all variables, of which $\mathrm{p}$ value in unvaried analysis is less or equal to $20 \%$, due to the exploratory nature of the study. The break-even point in terms of significance was $5 \%$ and confidence gap rated at $95 \%$.

\section{Ethical Considerations}

Each patient or his/her next of kin submitted a written notice of consent upon explanation of the research objectives and modalities. Moreover, patients' right as well as confidentiality was highly respected.

\section{Results}

All in all, 251 patients were enrolled. They were aged between 50 to 86 years with an average of 61 years \pm 8.1 . There were 130 (51.8\%) males against 121 females (48.2\%) meaning a sex-ratio of 1.07. The other socio-demographic characteristics are shown in Table 1.

Clinically, 59 (23.5\%) complain of mental disorders. 173 (68.9\%) and 73 (29.1\%) respectively had hypertension and stroke past records. Table 2 shows the population clinical characteristics. 28 (11.2\%) out of the 251 patients enrolled had MMSE score below or equal to 24. Indeed, 22 out of the 28 patients matched DSM IV dementia criteria, representing $8.8 \%$ (Figure 2). The prevalence was $5.3 \%$ with patients aged below 60 and $12.7 \%$ with those aged above 60 (Figure 3). All the 22 patients suffering from dementia were aged between 55 and 84, meaning an average age of $66 \pm 9.1$. There were 11 males (50\%) and 11 females (50\%). 18 (81.2\%) were married; 21 (95.5\%) lived in a family and 9 (41.0\%) already retired from work. Table 3 shows the classification of other socio-demographic characteristics of dementia patients. $18.2 \%$ revealed to have behavioral and mental disorders. Table 4 shows clinical characteristics of dementia patients. Total MMSE score varied from 7 to 23 with a median of 22. Table 5 shows the classification of MMSE various items of dementia patients. 19 (86.3\%) showed memory disorders against 13\% showing temporal and spatial disorders. Table 6 shows the prevalence rate of cognitive disorders of dementia patients. Etiologically, 6 (27.3\%) and 11 (50\%) suffered respectively from curable and degenerative dementia. Figure 4 shows classification of dementia etiologies. Within curable etiologies, there were three chronic hydrocephaly cases, two chronic subdural hematomas and a single cerebral tumor (Figure 5). 


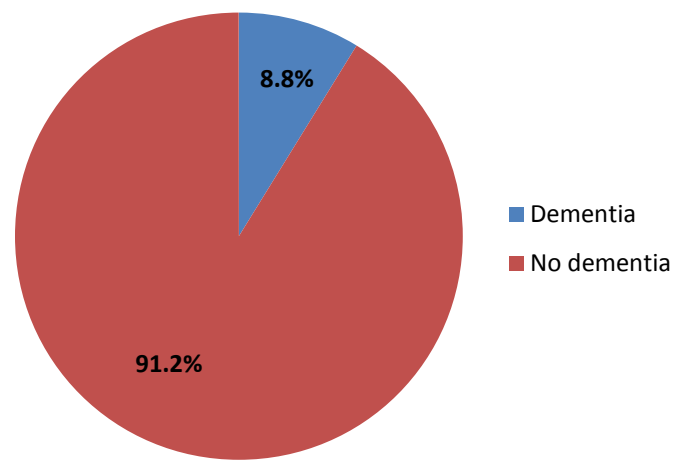

Figure 2. Dementia prevalence, Cotonoou 2013.

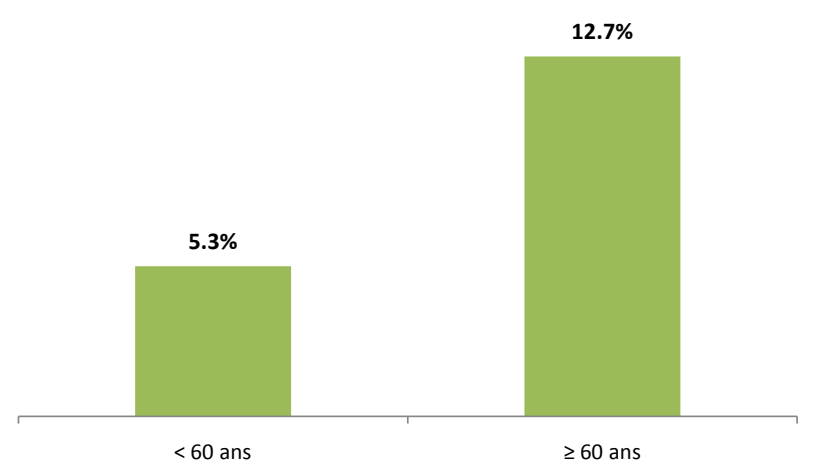

Figure 3. Dementia prevalence as per age, Cotonou 2013.

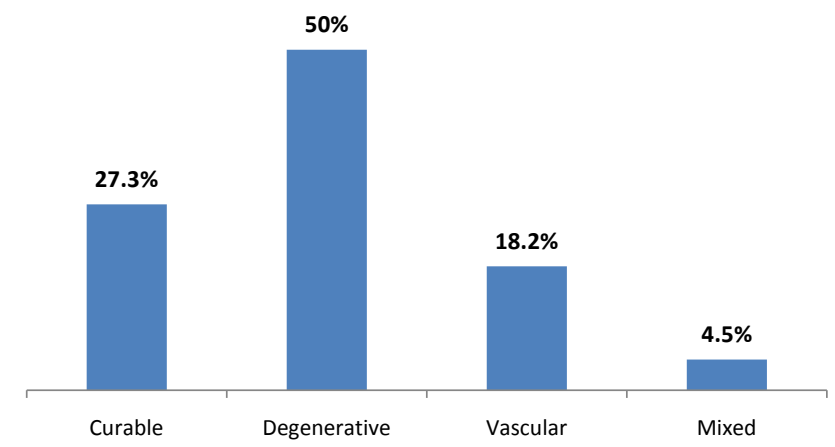

Figure 4. Classification of dementia etiologies, Cotonou 2013.

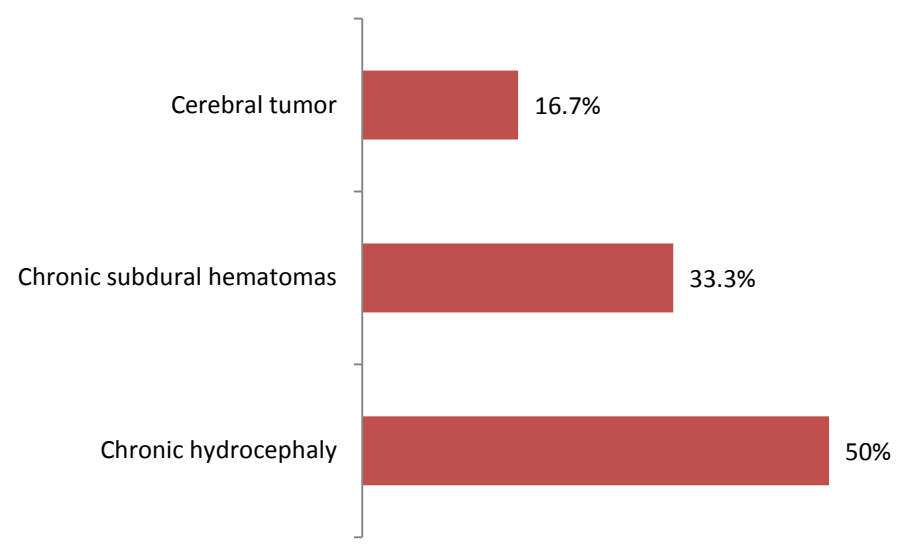

Figure 5. Classification of curable dementia etiologies, Cotonou 2013. 
Table 1. Socio-demographic characteristics of the population, Cotonou 2013.

\begin{tabular}{|c|c|}
\hline & Percentage \\
\hline \multicolumn{2}{|l|}{ Marital status } \\
\hline Married & $75.7 \%$ \\
\hline Widower & $15.9 \%$ \\
\hline Single & $4.3 \%$ \\
\hline Divorced & $1.1 \%$ \\
\hline \multicolumn{2}{|l|}{ Life pattern } \\
\hline Lives in family & $88.8 \%$ \\
\hline Lives alone/single life & $11.2 \%$ \\
\hline \multicolumn{2}{|l|}{ Residence } \\
\hline Urban locality & $85.3 \%$ \\
\hline Rural locality & $14.7 \%$ \\
\hline \multicolumn{2}{|l|}{ Level of education } \\
\hline Uneducated & $10.4 \%$ \\
\hline Primary & $25.9 \%$ \\
\hline Secondary & $38.6 \%$ \\
\hline University & $25.1 \%$ \\
\hline \multicolumn{2}{|l|}{ Profession } \\
\hline Civil servant & $24.7 \%$ \\
\hline Private worker & $11.2 \%$ \\
\hline Craftsman & $9.6 \%$ \\
\hline Housewife & $17.5 \%$ \\
\hline Retired & $30.7 \%$ \\
\hline Trader & $63 \%$ \\
\hline
\end{tabular}

Table 2. Clinical characteristics of the population, Cotonou 2013.

\begin{tabular}{ccc}
\hline Clinical characteristics & Total & Percentage \\
\hline Motive of consultation & 59 & $23.5 \%$ \\
Mental disorders & 21 & $8.4 \%$ \\
Behavioral disorders & & \\
Past records & 173 & $68.9 \%$ \\
Hypertension & 42 & $16.7 \%$ \\
Diabetes & 58 & $23.1 \%$ \\
Obesity & 59 & $23.5 \%$ \\
Hyperlipidemia & 21 & $8.4 \%$ \\
Cardiomyopathy & 10 & $3.9 \%$ \\
Epilepsy & 73 & $29.1 \%$ \\
Stroke & 17 & $6.8 \%$ \\
Smoking & 71 & $28.3 \%$ \\
Alcoholism & &
\end{tabular}


Table 3. Socio-demographic characteristics of dementia patients, Cotonou 2013.

\begin{tabular}{|c|c|c|}
\hline & Total & Percentage (\%) \\
\hline \multicolumn{3}{|l|}{ Matrimonial status } \\
\hline Single & 2 & $9.1 \%$ \\
\hline Married/concubine & 18 & $81.8 \%$ \\
\hline Widower & 2 & $9.1 \%$ \\
\hline \multicolumn{3}{|l|}{ Life pattern } \\
\hline Lives alone/Single & 1 & $4.5 \%$ \\
\hline Lives in family & 21 & $95.5 \%$ \\
\hline \multicolumn{3}{|l|}{ Profession } \\
\hline Civil servant & 1 & $4.5 \%$ \\
\hline Private worker & 3 & $13.6 \%$ \\
\hline Craftsman & 2 & $9.1 \%$ \\
\hline Housewife & 6 & $27.3 \%$ \\
\hline Retired & 9 & $41.0 \%$ \\
\hline Trader & 1 & $4.5 \%$ \\
\hline \multicolumn{3}{|l|}{ Residence } \\
\hline Urban locality & 18 & $81.8 \%$ \\
\hline Rural locality & 4 & $18.2 \%$ \\
\hline Other & 7 & $31.8 \%$ \\
\hline \multicolumn{3}{|l|}{ Level of education } \\
\hline Uneducated & 5 & $22.7 \%$ \\
\hline Primary & 6 & $27.3 \%$ \\
\hline Secondary & 6 & $27.3 \%$ \\
\hline Higher & 5 & $22.7 \%$ \\
\hline
\end{tabular}

Table 4. Clinical characteristics of dementia patients, Cotonou 2013.

\begin{tabular}{ccc}
\hline Clinic characteristics & Total & Percentage \\
\hline Motive of consultation & 4 & $18.2 \%$ \\
Mental disorders & 4 & $18.2 \%$ \\
Behavioral disorders & & \\
Past records & 16 & $72.7 \%$ \\
Hypertension & 3 & $13.6 \%$ \\
Diabetes & 6 & $27.3 \%$ \\
Obesity & 5 & $22.7 \%$ \\
Hyperlipidemia & 3 & $14.3 \%$ \\
Cardiomyopathy & 1 & $4.5 \%$ \\
Epilepsy & 14 & $63.6 \%$ \\
Stroke & 4 & $18.2 \%$ \\
Smoking & 5 & $22.7 \%$ \\
Alcoholism & & \\
\hline
\end{tabular}


Table 5. MMSE characteristics of dementia patients, Cotonou 2013.

\begin{tabular}{cc}
\hline MMSE items & Median score [Mini - Max $]$ \\
\hline Time orientation & $4[0-5]$ \\
Space orientation & $4[0-5]$ \\
Learning & $3[2-3]$ \\
Attention and calculation & $0[0-2]$ \\
Memory retention & $0[0-1]$ \\
Language & $7[2-8]$ \\
Constructive practices & $1[0-1]$ \\
\hline
\end{tabular}

Table 6. Classification of cognitive disorders in dementia population, Cotonou 2013.

\begin{tabular}{ccc}
\hline Types of disorder & Total & Percentage \\
\hline Time orientation & 13 & $59.1 \%$ \\
Space orientation & 13 & $59.1 \%$ \\
Learning & 1 & $4.6 \%$ \\
Attention and calculation & 21 & $95.4 \%$ \\
Memory retention & 19 & $86.3 \%$ \\
Language & 14 & $63.6 \%$ \\
Constructive practices & 6 & $27.3 \%$ \\
\hline
\end{tabular}

\subsection{Factors Associated with Dementia}

The only one socio-demographic factor associated with dementia was age exceeding 60 years (IC 95\% $=2.61$ [1.03 - 6.67], $\mathrm{p}=0.036$ ). Table 7 shows such data.

Clinically, stroke past records (IC 95\% $=5.04$ [2.01 - 12.62], $\mathrm{p}=0.0001$ ) and smoking (IC 95\% $=3.69$ [1.09 12.50], $\mathrm{p}=0.049$ ) were closely associated with dementia as shown in Table 8.

\subsection{Predictive Factors of Dementia}

After multi-varied analysis of associated variables in unvaried analysis, those which are individually associated with mortality were stroke past records (IC 95\% $=7.66$ [2.46 - 23.85], $\mathrm{p}=0.0001$ ), and smoking (IC 95\% = 6.05 [1.26 - 29.38], $\mathrm{p}=0.001)$. Table 9 shows these data.

\section{Discussion}

It was a cross-sectional, descriptive and analytical research. The method we implemented is really adapted to this kind of research in the sense that, there was no plan to follow-up the patients; instead the strategy was to conduct a questionnaire after consultation. During the research period, we exhaustively screened all patients fulfilling our inclusion criteria. This enabled us incorporate 251 patients. However, only 22 patients showed dementia based on DMS IV diagnosis criteria. Such a small number of patients did not allow us highlight some factors associated with dementia, which were however observed in the paper.

\subsection{Prevalence}

In our research dementia prevalence was $8.8 \%$. This result is close to $8.1 \%$ obtained by Mbelesso et al. [8] in a cross-sectional research conducted in the $3^{\text {rd }}$ district of Bangui (Central African Republic) in 2012, on dementia epidemiology in elderly population. Similarly, Molero et al. [9] recorded in 2007 a prevalence of $10.3 \%$ in a re- 
Table 7. Socio-demographic factors associated with dementia, Cotonou 2013.

\begin{tabular}{|c|c|c|c|c|}
\hline & Dementia n (\%) & No dementia n (\%) & RC [IC 95\%] & $\mathrm{p}$ value \\
\hline Age & & & & $0.036^{*}$ \\
\hline$<60$ years & 7 (5.3\%) & $126(94.7 \%)$ & 1 & \\
\hline$\geq 60$ years & 15 (12.7\%) & 103 (87.3\%) & $2.61[1.03-6.67]$ & \\
\hline Sex & & & & 0.860 \\
\hline Male & $11(8.5 \%)$ & 119 (91.5\%) & 1 & \\
\hline Female & $11(9.1 \%)$ & 110 (90.1\%) & 1.08 [0.45 - 2.59] & \\
\hline Marital status & & & & 0.390 \\
\hline Single & $2(18.2 \%)$ & $9(81.8 \%)$ & 1 & \\
\hline Married & $18(9.5 \%)$ & 172 (90.5\%) & 2.12 [0.42 - 1059] & \\
\hline Widower & $2(5 \%)$ & 38 (95\%) & $0.50[0.11-2.25]$ & \\
\hline Divorced & $0(0 \%)$ & $10(100 \%)$ & - & \\
\hline Life pattern & & & & 0.250 \\
\hline Lives alone & $1(3.6 \%)$ & 27 (96.4\%) & 1 & \\
\hline Lives in family & $21(9.4 \%)$ & 202 (90.6\%) & $2.80[0.36-21.71]$ & \\
\hline Profession & & & & 0.160 \\
\hline Civil servant & $1(1.6 \%)$ & 61 (98.4\%) & 1 & \\
\hline Private worker & $3(10.7 \%)$ & 25 (89.4\%) & $7.32[0.73$ - 73.78] & \\
\hline Craftsman & $2(8.3 \%)$ & 22 (91.7\%) & $5.54[0.47-64.22]$ & \\
\hline Housewife & $6(13.6 \%)$ & 38 (86.7\%) & 9.63 [1.11 - 83.13] & \\
\hline Retired & $9(11.7 \%)$ & 68 (88.3\%) & 4.35 [0.25 - 73.98] & \\
\hline Trader & $1(6.2 \%)$ & 15 (93.7\%) & 8.07 [0.99 - 65.58] & \\
\hline Education level & & & & 0.295 \\
\hline Uneducated & $5(19.2 \%)$ & $21(80.8 \%)$ & 1 & \\
\hline Primary & $6(9.2 \%)$ & 59 (90.1\%) & 4.31 [0.35 - 63.98] & \\
\hline Secondary & $6(6.2 \%)$ & 91 (93.8\%) & $2.80[0.36-21.71]$ & \\
\hline Higher & $5(7.9 \%)$ & 58 (92.1\%) & $0.50[0.11-2.25]$ & \\
\hline
\end{tabular}

*Significant result.

search conducted on elderly population living on the Caribbean coast of Venezuela. In 2012, Coume M. et al. [7] recorded $10.8 \%$ as prevalence rate in a cross-sectional research on the estimation of cognitive prevalence within an elderly Senegalese population. Our record of $8.8 \%$ dementia prevalence is lower than $24.3 \%$ registered by Uwakwe R. et al. [10] in a cross-sectional research conducted in 2009 on dependency epidemiology in elderly Nigerian population. It is also lower than $43.2 \%$ recorded by Ndiaye et al. [11] in a research conducted from January 2004 to June 2005 on the operation of a Senegalese memory clinic in Fann teaching hospital psychiatry department (Dakar, Senegal). In fact, many reasons may justify this difference in terms of the prevalence rate. First of all, in Uwakwe R. et al. [10] research, patients were aged 65 and above and the sample was made up of 1238 patients who went through 10/66 protocol; knowing that the specificity and sensitivity of such a protocol are higher than those of MMSE we implemented. The same goes with Ndiaye et al. [11] who utilized in their research Senegal Test, which sensitivity and specificity are higher than those of MMSE. Moreover, in their re- 
Table 8. Clinical factors associated with dementia, Cotonou 2013.

\begin{tabular}{|c|c|c|c|c|}
\hline & Dementia n (\%) & No dementia n (\%) & RC [IC 95\%] & $\mathrm{p}$ value \\
\hline Hypertension & & & & 0.68 \\
\hline Yes & 16 (9.3\%) & 157 (90.7\%) & $1.22[0.46-3.23]$ & \\
\hline No & $6(7.7 \%)$ & 72 (92.3\%) & 1 & \\
\hline Diabetes & & & & 0.67 \\
\hline Yes & $3(7.1 \%)$ & 39 (92.9\%) & $0.76[0.22-2.73]$ & \\
\hline No & 19 (9.1\%) & 190 (90.9\%) & 1 & \\
\hline Obesity & & & & 0.63 \\
\hline Yes & $6(10.3 \%)$ & $52(89.7 \%)$ & $1.28[0.45-3.42]$ & \\
\hline No & $16(8.3 \%)$ & 177 (91.7\%) & 1 & \\
\hline Epilepsy & & & & 0.89 \\
\hline Yes & $1(10 \%)$ & $9(90 \%)$ & $1.2[0.14-9.64]$ & \\
\hline No & $21(8.7 \%)$ & $220(91.3 \%)$ & 1 & \\
\hline Stroke past records & & & & $0.0001^{*}$ \\
\hline Yes & $14(19.2 \%)$ & 59 (80.8\%) & $5.04[2.01-12.62]$ & \\
\hline No & $8(4.5 \%)$ & 170 (95.5\%) & 1 & \\
\hline Smoking & & & & $0.049^{*}$ \\
\hline Yes & $4(23.5 \%)$ & $13(76.5 \%)$ & $3.69[1.09-12.50]$ & \\
\hline No & $18(7.7 \%)$ & $216(92.3 \%)$ & 1 & \\
\hline Alcoholism & & & & 0.53 \\
\hline Yes & $5(7.0 \%)$ & $66(93.0 \%)$ & $0.72[0.26-2.05]$ & \\
\hline No & 17 (9.4\%) & $163(90.6 \%)$ & 1 & \\
\hline
\end{tabular}

*Significant result.

Table 9. Dementia predictive factors. Results of multi-varied analysis, Cotonou 2013.

\begin{tabular}{cccccc}
\hline Variables & Total & Dementia (n\%) & $\mathrm{RC}_{\text {Gross }}\left[\mathrm{IC}_{95 \%}\right]$ & $\mathrm{RC}_{\text {adjusted }}\left[\mathrm{IC}_{95 \%}\right]$ & $\mathrm{p}$ value \\
\hline Stroke & & & & & $\mathbf{0 . 0 0 0 1}^{*}$ \\
Yes & 73 & $14(19.2)$ & $5.04[2.01-12.62]$ & $7.66[2.46-23.85]$ & \\
No & 178 & $8(4.5)$ & 1 & 1 & $\mathbf{0 . 0 0 1}^{*}$ \\
Smoking & & & & \\
Yes & 17 & $4(23.5)$ & $3.69[1.09-12.50]$ & $6.05[1.26-29.38]$ & \\
No & 234 & $18(7.7)$ & 1 & 1 & \\
\hline
\end{tabular}

search, enrolled patients (132 in total) were selected among those who showed memory disorders. All this could explain the higher rate recorded in these two researches. Notwithstanding our 8.8\% prevalence is higher than the figure recorded by other authors. Thus, Paraïso et al. [6] recorded 2.6\% in rural area (Djidja) and 3.7\% in urban area (Cotonou) in a door-to-door research conducted in Benin in 2010 on dementia epidemiology with patients aged 65 and above, whilst Guerchet et al. [12] recorded 6.7\% in a cross-sectional research conducted in the year 2012 on dementia epidemiology within elderly population living in Brazzaville (Congo). Longdon et al. [13] 
registered 6.4\% prevalence in a cross-sectional community research on dementia prevalence in rural Tanzania. El Tallawy et al. [14] also registered 2.3\% in a research conducted in 2011 on dementia prevalence in Kharga (Egypte) in 2012, whilst Yusuf et al. [15] estimated dementia prevalence at $2.8 \%$ in a community research on dementia prevalence and subtypes dementia within elderly population living in northern Nigeria. These prevalence rates which are very lower than what we recorded in our research could be explained by the fact that most of these researches were conducted within a vast population with samples above 1000 patients (1198, 8173, and 1139 patients were respectively enrolled by Longdon, El Tallawy and Paraïso). In addition, the test utilized in these researches is CSID, which has a weaker specificity than MMSE.

\subsection{Socio-Demographic Characteristics}

In our research dementia patients average age was 66 years \pm 9.1 . This result is close to 67 years \pm 17 observed by Ndiaye et al. [11] as well as 67 years $\pm 7.5 \%$ recorded by Coume et al. [7]. The same result is lower to 76 years \pm 7.1 recorded by Guerchet et al. [12]. This result is explained by the fact that the patients enrolled in the research were 65 years and above against 50 years and above in our research. It comes out that age is the sole risk factor which was corroborated. In our research, 62\% of dementia patients were aged beyond 60 years. Moreover, dementia prevalence increased with age. The figure varied from 5.3\% below 60 years to $12.7 \%$ beyond 60 years. El Tallawy [14] recorded that dementia prevalence of $2.3 \%$ increased drastically to $18.5 \%$ with subjects aged beyond 80 years. Libre et al. [16] confirmed that beyond 65 years, dementia prevalence doubles anytime age increases by 5 years. Other authors such as Longdon, Coume, Yusuf et Paraïso [6] [7] [13] [15] recorded similar results. Out of 22 dementia patients 11 were males; meaning a sex ratio of 1 . This result is dissimilar to the ratio recorded by most researches which revealed a female predominance. Thus, Mbeleso et al. [8] recorded 82.35\% female predominance whilst Stewart et al. [17] recorded 60.8\%. Letenneur et al. [18] as well as Nitrini et al. [19] corroborated this female predominance which according to Stewart et al. [17] might be explained by the biological and hormonal differences between the two sexes, particularly estrogens. Our result which is quite different from others' could be explained by the fact that the population was male biased and not large enough. Indeed 18 (81.8\%) of dementia patients were married. This result is similar to that of Ndiaye et al. (76.5) and Coume et al. (79\%). However, it is different from most authors' findings. Thus, Fratiglioni [20] maintains that being a widower or a divorcee implies an under-performance regarding MMSE; such under-performance is not recorded with elderly married persons. We could then bring up the hypothesis of marriage playing a role of social balance. Van Gelder et al. [21] in a research conducted in 2006 in Finland noted that men who lost their partner, those who weren't married and those who live single life or lived single life for at least 5 years were much more exposed to cognitive decline, unlike married men or men who lived with a partner. This predominance of married persons has its explanation in our socio-cultural realities. In fact, it is rare to see persons aged 50 and above who are not married. Out of the 22 dementia patients, 21 (95.5\%) lived in a family. Fratiglioni et al. [20] proved that single patients were twice exposed to dementia comparing to those living in a family. They also found out that a closed social network increases by $60 \%$ the risk. Dementia risk is therefore correlated with the significance of social network. Baiyewu et al. [3] exposed that in Africa elderly persons live in extended family made up of several generations. 6.7\% live alone; which contrast the prevalence rate in Europe (35\% - 39\%). Our results reflect the importance of social network in Africa particularly in Benin. Such a rich social network may explain the low dementia prevalence in our societies. Unfortunately, this social network tends to ebb with a progressive urbanized lifestyle leading to individualism. However, we should not forget that these maladies are under-diagnosed. 5 (22.7\%) of the dementia patients were uneducated. Among the 17 (77.3\%) who were educated, 6 (27.3\%) had primary education only. In Egypt, El Tallawy et al. [14] conducted a research which revealed that dementia prevalence rate was significantly higher among uneducated persons $(6.35 \%)$ than literate persons (0.6\%). They asserted that the low education level played a predominant role in dementia occurrence in elderly population especially when they did not reach elementary school. This assertion is supported by Guerchet et al. who demonstrated that, not acquiring elementary education was significantly associated with dementia. On the contrary, a research conducted in Kenya revealed that there was no proof of little education being associated with dementia occurrence [22].

\subsection{Dementia Etiologies}

Results from our research revealed that degenerative dementia cases (50\%) were mostly prevalent, followed by 
vascular dementia (31.8\%) then curable dementia (27.3\%) and finally mixed dementia (18.2\%). This result is similar to that of Shelley et al. [23] who recorded $57.1 \%$ and $26.9 \%$ respectively for degenerative and vascular dementia. Alzheimer disease (AD) is the commonest neurodegenerative dementia; it is cortically predominant and represents dementia major cause in elderly population. AD is fundamentally caused by two types of cerebral lesions: senile plaques and fibrillary neurodegeneration. Senile plaques are extracellular deposits of amyloidal substance, mostly made up of peptide polymer $\mathrm{A} \beta$ (or $\beta$-amyloidal). This substance settles down progressively in the brain predominantly in the gray substance. These insoluble deposits are not metabolized by the body and destroy progressively adjacent nervous fibers. Parallel to this, in the fibrillary degeneration process, pathologic filaments made of protein build up around the cell body of the neurons. These neurons depolymerize then aggregate in the cytoplasm. Generally, this degeneration begins from the hippocampus and spreads across temporal regions. Other researches also revealed a high prevalence of AD. Thus, Yusuf et al. [15] recorded 66.7\% AD while Alladi et al. [24] and Shelley et al. [23] respectively recorded 38.39\% and 52.6\%. Vascular dementia (VD) was the second etiology of dementia syndromes after degenerative dementia of Alzheimer type. Vascular dementia encompasses the whole dementia states secondary to cerebrovascular lesions. El Tallawy et al. [14] recorded $28.7 \%$ of vascular dementia cases. They are caused by the consequences of cerebrovascular affection (blockage of vessels or cerebral hemorrhage). In general they worsen discretely (during a new stroke occurrence). Neuro-imaging plays a predominant role in diagnosing by showing lesions of vascular origin. Curable dementia cases are those of which the etiology was identified. The most frequent causes are neurosurgical: cerebral tumors, adult hydrocephaly, and subdural hematoma. These causes are easily revealed by the neuro-imaging. The systematic results of research about infectious dementia (mainly syphilis, HIV-Aids or hardly ever Whipple disease), endocrine or deficient dementia are rarely productive because these types of dementia can totally be reversible. The discovery of curable cause for dementia does not always guarantee a complete recovery from the disease. However, systematic results from the research allow finding and treating reversible concomitant affections and disorders which can contribute to worsening dementia.

\subsection{Factors Associated with Dementia}

In our research two factors were revealed to be associated with dementia. There were stroke past records and smoking. 63.6\% had stroke. This result is similar to the record of the University of Oxford in the United Kingdom [25], following a research conducted by the department of research on diseases prevention with stroke inpatients. The prevalence of dementia with these patients was comparable to the rate of prevalence recorded with stroke free patients who were 10 years older. Only one stroke occurrence provokes no diffuse decline of cognitive functions leading to dementia. It is the repetitive occurrence of such incidents with the same patient which can provoke cognitive decline. We then refer to multiple infarction dementia or multi-infarction dementia. In a research conducted by Altieri et al. [26], about 30\% of stroke survivors suffered from dementia thereafter. The risk is high after stroke occurrence, but it is higher even after the embolic thrombosis occurrence. Post stroke dementia risk factors are not well known. However, three theoretical reasons could explain post stroke dementia occurrence. First of all, dementia could be the direct consequence of cerebral lesions of vascular origin. Then it could be due to the combination of degenerative lesions of Alzheimer type in a pre-clinical stage; some post stroke dementia states are progressive. Finally, white substance anomalies could also contribute to the decline in the sense that, they are associated with a high risk of vascular relapses and could stimulate neuropsychological disorders. Vascular lesions, white substance and lesions of Alzheimer type anomalies all put together, could stimulate post stroke dementia occurrence [27]. 18\% were addicted to smoking. This result is similar to Juan et al. [28] findings, as they maintained that smoking revealed to be a risk factor. Likewise, Rusanen et al. [29] in 2011 established that smoking increases Alzheimer disease risk occurrence by 2. These Finnish scientists conducted a broad research between 1978 and 2008. In this research, 21,123 patients aged 50 to 60 years were thoroughly followed during 23 years. They diagnosed 5367 senile dementia cases of which 1136 Alzheimer diseases. Having reviewed different risk factors associated with dementia, researchers discovered that smoking played an important role. In fact, dementia risk increased by hundred percent (100\%) concerning heavy smokers consuming over two packets of cigarette a day. Globally, smokers presented a risk of vascular dementia multiplied by 2.72 . The same researchers showed that smoking affected the brain directly and increased both oxidative stress and inflammation which were two risk factors related to Alzheimer disease [29]. Nonetheless, the effect of smoking in dementia occurrence is not well explained. We only know that smoking has cerebrovascular effects 
and amplifies the cholinergic metabolism by dysfunctioning brain nicotine receptacles. A Chinese research [30] proved that second-hand smoking constitutes a risk factor which could increase by $29 \%$ the occurrence of severe dementia.

\section{Conclusion}

Dementia with elderly population aged 50 and above, remains a pathology to which very little attention is paid in Benin health system. This research through its theme originality highlights dementia in the intention of developing adapted and effective national strategies to combat it. There is a need to conduct other researches about this theme in developing countries, where, just like in the case of Benin no consideration is given to this pathology.

\section{References}

[1] Napon, C., Traore, S., Idris, S., Niakara, A., Ouango, G.G., Kabré, A., et al. (2009) Dementia in Sub-Saharan Africa: Clinic and Etiological Aspects in Ouagadougou Hospital (Burkina Faso). African Journal of Neurological Sciences, 28, $1-5$.

[2] Ferri, C.P. (2005) Global Prevalence of Dementia. Delphy Consensus Study, 366, 2112-2117.

[3] Baiyewu, O., Bella, A.F., Adeyemi, J.D., Bamgboye, E.A., Ikuesan, B.A. and Jegede, R.O. (1997) Health Problems and Socio-Demographic Findings in Elderly Nigerians. African Journal of Medicine and Medical Sciences, 2, 13-17.

[4] Touré, K., Coumé, M., Ndiaye-Ndongo, N.D., Thiam, M.H., Zunzunegui, M.V., Bacher, Y., et al. (2008) Dementia Prevalence in a Senegalese Elderly Population. African Journal of Neurological Sciences, 27, 15-22.

[5] Avode, D.G., Gandaho, P., Da-Cruz, P.C., Ahyi, R.G. and Zohoun, Th. (1998) Senile Dementia in Cotonou Hospital. Le Bénin Médical, 7, 23-27.

[6] Paraïso, M.N. (2010) Dementia Epidemiology in Elderly Benin Population Aged 65 and Above (Afrique de l’Ouest). $\mathrm{Ph} . \mathrm{D}$. Heath Science Biology. University of Limoges, Limoges, 486p.

[7] Coume, M., Touré, K., Thiam, M.H., Zunzunegui, M.V., Bacher, Y., Diop, T.M., et al. (2012) Evaluation of Cognitive Deficiency Prevalence in Elderly Population in a Senegalese Health Center "Institution Retraite”. Geriatr Psychol Neuropsychiatr Vieil, 10, 39-46.

[8] Mbelesso, P., Tabo, A., Guerchet, M., Mouanga, A.M., Bandzouzi, B., Houinato, D., et al. (2012) Dementia Epidemiology in Elderly Population Living in Bangui 3rd Municipality (Central Africa Republic)]. Bulletin de la Société de pathologie exotique, 105, 388-395. http://dx.doi.org/10.1007/s13149-012-0247-8

[9] Molero, A.E., Pino-Ramirez, G. and Maestre, G.E. (2007) High Prevalence of Dementia in a Caribbean Population. Neuroepidemiology, 29, 107-112. http://dx.doi.org/10.1159/000109824

[10] Uwakwe, R., Ibeh, C.C., Modebe, A.I., Bo, E., Ezeama, N., Njelita, I., et al. (2009) Dependence Epidemiology in Elderly Population in Nigeria: Prevalence, Determinants, Informal Care and the Use of Health Services; Research Group 10/66 Dementia. Journal of the American Geriatrics Society, 57, 1620-1627. http://dx.doi.org/10.1111/j.1532-5415.2009.02397.x

[11] Ndiaye, N.N.D., Sylla, A., Touré, K., Thiam, M.H. and Gueye, M. (2011) Operations Assessment in a Senegalese Memory Clinic, Fann Teaching Hospital Psychiatric Department (Dakar, Senegal). African Journal of Neurological Sciences, 30, 2-10.

[12] Guerchet, M., Houinato, D., Paraiso, M.N., von-Ahsen, N., Nubukpo, P., Otto, M., et al. (2009) Dementia and Cognitive Disorders in Elderly Population Living in Benin Rural Areas, West Africa. Dementia and Geriatric Cognitive Disorders, 27, 34-41. http://dx.doi.org/10.1159/000188661

[13] Longdon, A.R., Paddick, S.M., Kisoli, A., Dotchin, C., Gris, W.K., Dewhurst, F., et al. (2013) Dementia Prevalence in Rural Tanzania: A Community Cross-Sectional Research. International Journal of Geriatric Psychiatry, 28, 728-737. http://dx.doi.org/10.1002/gps.3880

[14] El-Tallawy, H.N., Farghly, W.M., Shehata, G.A., Rageh, T.A., Hakeem, N.A., Abo-Elfetoh, N., et al. (2012) Dementia Prevalence in Kharga District Al, New Valley Governorate, Egypt. Neuroepidemiology, 38, 130-137. http://dx.doi.org/10.1159/000335655

[15] Yusuf, A.J., Baiyewu, O., Sheikh, T.L. and Shehu, U.A. (2011) Prevalence of Dementia and Sub-Types of Dementia in a Northern Nigerian Elderly Population. International Psychogeriatrics, 3, 379-386. http://dx.doi.org/10.1017/S1041610210001158

[16] Llibre-Rodriguez, J.J., Ferri, C.P., Acosta, D., Guerra, M., Huang, Y., Jacob, K.S., et al. (2008) 10/66 Dementia Research Group. Prevalence of Dementia in Latin America, India, and China: A Population-Based Cross-Sectional Sur- 
vey. Lancet, 372, 464-474. http://dx.doi.org/10.1016/S0140-6736(08)61002-8

[17] Stewart, R., Kim, J., Shin, S. and Yoon, J. (2003) Education and the Association between Vascular Risk Factors and Cognitive Function. A Cross-Sectional Study in Older Koreans with Cognitive Impairment. International Psychogeriatrics, 15, 27-36. http://dx.doi.org/10.1017/S1041610203008731

[18] Letenneur, L., Gilleron, V., Commenges, D., Helmer, C., Orgogozo, J.M. and Dartigues, J.F. (1999) Are Sex and Educational Level Independent Predictors of Dementia and Alzheimer's Disease? Incidence Data from the PAQUID Project. Journal of Neurology, Neurosurgery \& Psychiatry, 66, 177-183. http://dx.doi.org/10.1136/jnnp.66.2.177

[19] Nitrini, R., Caramelli, P., Herrera, E., Bahia, V.S., Caixeta, L.F., Radanovic, M., et al. (2004) Incidence of Dementia in A Community-Dwelling Brazilian Population. Alzheimer Disease and Associated Disorders, 18, 241-246.

[20] Fratiglioni, L., Paillard-Borg, S. and Winblad, B. (2004) An Active and Socially Integrated Lifestyle in Late Life Might Protect against Dementia. The Lancet Neurology, 3, 343-353. http://dx.doi.org/10.1016/S1474-4422(04)00767-7

[21] Van-Gelder, B,M., Tijhuis, M., Kalmijn, S., Giampaoli, S., Nissinen, A. and Kromhou, D. (2006) Marital Status and Living Situation During a 5-Year Period Are Associated With a Subsequent 10-Year Cognitive Decline in Older Men: The FINE Study. The Journals of Gerontology, 61, 213-219. http://dx.doi.org/10.1093/geronb/61.4.P213

[22] Chen, C.H., Mizuno, T., Elston, R., Kariuki, M.M., Hall, K., Unverzagt, F., et al. (2010) Comparative Study to Screen Dementia and APOE Genotypes in an Ageing East African population. Neurobiology Aging, 31, 732-740. http://dx.doi.org/10.1093/geronb/61.4.P213

[23] Shelley, B.P. and Al-Khabouri, J. (2007) Dementia Spectrum: Prevalence, Causes and Clinic Profile. A National Reference; Research in Oman Hosptial. Dementia and Geriatric Cognitive Disorders, 24, 280-287. http://dx.doi.org/10.1159/000107494

[24] Alladi, S., Mekala, S., Chadalawada, S.K., Jala, S., Mridula, R. and Kaul, S. (2011) Dementia Subtypes Divisions: A Study from an Indian Memory Clinic. Dementia and Geriatric Cognitive Disorders, 32, 32-38. http://dx.doi.org/10.1159/000329862

[25] Pendlebury, S.T. (2012) Dementia in Patients Hospitalized with Stroke: Rates, Time Course, and Clinico-Pathologic Factors. International Journal of Stroke, 7, 570-581.

[26] Altieri, M., Di-Piero, V., Pasquini, M., Gasparini, M., Vanacore, N., Vicenzini, E., et al. (2004) Delayed Post Stroke Dementia. A 4-Year Follow-Up Study. Neurology, 62, 2193-2197. http://dx.doi.org/10.1212/01.WNL.0000130501.79012.1A

[27] Pasquier, F. and Leys, D. (1997) Post Stroke Dementia Mechanism. Blood Thrombosis Vessels, 9, 220-226.

[28] Juan, D., Zhou, D.H., Li, J., Wang, J.Y., Gao, C. and Chen M.A. (2004) 2-Year Follow-Up Study of Cigarette Smoking and Risk of Dementia. European Journal of Neurology, 11, 277-282. http://dx.doi.org/10.1212/01.WNL.0000130501.79012.1A

[29] Rusanen, M., Kivipelto, M., Quesenberry, C.P. and Whitmer, R.A. (2011) Heavy Smoking in Midlife and Long-Term Risk of Alzheimer Disease and Vascular Dementia. JAMA Internal Medicine, 171, 333-339.

[30] Dong, M.J., Peng, B., Lin, X.T., Zhao, J., Zhou, Y.R. and Wang, R.H. (2007) The Prevalence of Dementia in the People’s Republic of China: A Systematic Analysis of 1980-2004 Studies. Age Ageing, 36, 619-624.

http://dx.doi.org/10.1093/ageing/afm128

\section{Abbreviation List}

\begin{tabular}{cc}
\hline Abbreviations & Full meaning \\
\hline CNHU-HKM & Centre National Hospitalier et Universitaire Hubert Koutoukou Maga \\
MMSE & Mini Mental State Examination (MMSE) \\
DSM-IV & Diagnostic and Statistical Manuel of mental disorders, 4th edition \\
AD & Alzheimer Disease \\
VD & Vascular Dementia \\
HIV & Human Immunodéficiency Virus \\
\hline
\end{tabular}

